\title{
Electrodeposition of Superhydrophobic Hydroxyapatite/Magnesium Phosphate on a Magnesium Alloy Substrate for Enhanced Corrosion Resistance
}

\section{Jiajun Huang}

School of Civil Engineering and Architecture, Xinxiang University, Xinxiang, 453000, China

E-mail: huangjiajun_xx168@126.com

doi: $10.20964 / 2017.06 .01$

Received: 11 February 2017 / Accepted: 23 March 2017 / Published: 12 May 2017

\begin{abstract}
Magnesium phosphate-doped hydroxyapatite and magnesium hydrogen phosphate-doped dicalcium phosphate dihydrate superhydrophobic coatings were electrolytically deposited on an AZ91D alloy. The contact angles of water/oil were $155^{\circ} / 141^{\circ}$, respectively. In comparison with the bare substrate, electrochemical measurements of the superamphiphobic surfaces, including both EIS measurement and potentiodynamic polarization curves, all demonstrated a dramatic enhancement in the inhibition of surface corrosion.
\end{abstract}

Keywords: Magnesium alloy; Electrodeposition; Hydroxyapatite; Superhydrophobic coating; Corrosion

\section{$\underline{\text { FULL TEXT }}$}

(C) 2017 The Authors. Published by ESG (www.electrochemsci.org). This article is an open access article distributed under the terms and conditions of the Creative Commons Attribution license (http://creativecommons.org/licenses/by/4.0/). 